\title{
Air-puff-elicited startle: Habituation over trials and measurement of a hypothetical emotional response ${ }^{1}$
}

\author{
PETER F. GALVANI, ${ }^{2}$ UNIVERSITY OF \\ IOWA, lowa City, Iowa 52240
}

In the first of two experiments, it was demonstrated that an air puff elicited a reliable startle reflex in rats which showed no habituation over 50 trials. In the second study an attempt was made to measure an emotional response by recording startle reactions to the air puff during presentation of a presumed fear-eliciting CS. It was concluded that the air-puff-elicited startle reflex can be employed as an indirect measure of a hypothetical emotional response.

Variations in the magnitude of the startle reflex are used, on occasion, as indirect indicators or measures of hypothetical emotional responses. The theoretical rationale for this technique stems from the notion that emotional responses are drive producing. Accordingly, all stimulus-response tendencies, including the startle reflex, should be enhanced by their presence. Moreover, the degree of enhancement presumably varies directly with the animal's motivational level. Brown, Kalish, and Farber (1951) originally employed the startle reflex to monitor the acquisition of drive-like properties by a CS and found facilitation of rat startle responses by presumed fear-eliciting stimuli. Wagner (1963) demonstrated augmentation of the startle reflex by frustration elicitors. More recently, Hoffman and Searle (1965) have shown that presentations of auditory stimuli also augment the startle reaction.

The startle reflex in earlier studies was elicited generally by an auditory probe stimulus, typically a brief gunshot-like sound. In the present experiments the probe or startle stimulus was a brief puff of air delivered simultaneously to both the rat's face and its rear. Experiment 1 was a study of habituation of the startle response elicited by the air puff. Earlier investigations involving the startle response to auditory stimuli have generally shown a rather large habituatory decrement for startle (e.g., Moyer, 1963). In the second experiment an attempt was made to index an emotional response by recording startle responses to the air puff during presentation of a presumed fear-eliciting CS.

\section{EXPERIMENT 1}

Method

Subjects. Eight male albino rats weighing
$260-400 \mathrm{~g}$ served as Ss. These Ss had previously been used in an alley shock-escape study.

Apparatus. The apparatus used to record the startle reaction was a stabilimeter device, the basic sensing element of which was a postage scale (Hanson, Model 1509, 5-1b capacity) upon which was attached a platform, 3 in. wide and $7 \frac{1}{2}$ in. long, made of 1/16-in. aluminum. A grid, constructed of 15 stainless steel rods (3/32 in. diam) spaced at $1 / 2$-in. intervals in plastic side rails, was secured to the platform. Surmounting the grid was a detachable confinement box (33/4 in. wide, $71 / 4$ in. long, 5-3/8 in. high, inside dimensions) constructed of $1 / 8$-in. Plexiglas. The top and front of the box were clear; the back and two ends were black.

Startle movements caused vertical displacements of the box, its platform, and of an Astatic phonograph cartridge attached thereto. The steel needle appropriate to the cartridge was replaced by a 1 -in. rod having a $1.5 \mathrm{~g}$ weight at the end. This more massive "needle" tended, because of its inertia, to lag behind both upward and downward movements of the cartridge and thus to generate a voltage at the cartridge terminals. This signal was transmitted through a shielded cable to one channel of a Grass Model SC polygraph, where it was amplified by an EEG preamplifier (Model 5E) and recorded by the oscillograph pen at a paper speed of $25 \mathrm{~mm} / \mathrm{sec}$. A second channel was used as an event marker to record presentations of the startle stimulus. The startle response was measured as the maximum peak-to-peak pen deflection occurring within $0.4 \mathrm{sec}$ of the startle stimulus presentation. The system was calibrated by dropping weights ranging from 50 to $400 \mathrm{~g}$ in $50 \mathrm{~g}$ steps on the top of the confinement box from an approximate height of $1 / 4 \mathrm{in}$. The resulting calibration curve indicated that amplitude of pen deflection increased monotonically as a function of applied weight, the relation being approximately linear.

The startle stimulus, a 55- to $60 \mathrm{msec}$ air puff, was presented to the rat through 1-in.-diam holes in both ends of the narrow confinement box, so the rat would be puffed at both ends regardless of his orientation. The air was delivered through a pair of 3/16-in. brass nozzles, the ends of which were approximately $1 / 2$ in. from the holes in the ends of the box. The holes were centered about $2 \frac{13}{4}$ in. above the grid. The static pressure in the puff delivery system was capable of supporting a $115-\mathrm{mm}$ column of mercury with one nozzle open.

The presentations of the startle stimulus were controlled automatically by electromechanical programming equipment located outside the Industrial Acoustics Co. sound-treated room which housed the stabilimeter. One wall of the sound-treated room was provided with a window, which enabled $E$ to observe the behavior of $S$ throughout the experiment.

Procedure. Following $5 \mathrm{~min}$ of habituation to the apparatus, the eight rats each received 50 air-puff presentations in a single session, at an average interval of $80 \mathrm{sec}$ (range, 60-115). E rated S's behavior at the instant of puff presentation as either mobile (grooming, sniffing, turning around, etc.) or immobile (crouching, sitting, lying, etc.).

\section{Results and Discussion}

Figure 1 presents the mean startle-response magnitude for the eight rats over blocks of five trials. This function reveals no clear tendency toward habituation, an outcome at variance with findings obtained with auditory startle stimuli. A comparison of the startle responses obtained with an air puff and those previously recorded at Iowa with an auditory stimulus ${ }^{3}$ reveals considerably less variability in response magnitude with the former.

The correlation between S's body weight and startle response magnitude for $20 \mathrm{Ss}$ (including 12 Ss from another experiment) was essentially zero. The overall mean startle response for trials on which $\mathrm{S}$ was immobile, however, was greater than the

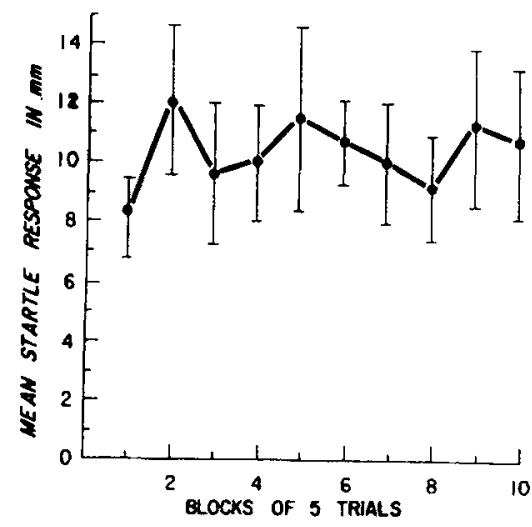

Fig. 1. Mean startle response in millimeters over blocks of five trials. Vertical lines represent $\pm 1 / 2 \sigma$. 
mean for trials on which $\mathrm{S}$ was mobile (12.5 vs 7.8 , respectively).

Figure 1 suggests that air-puff-elicited startle, unlike the response to an auditory probe, is particulary resistant to habituation. But the features of the procedure which minimize habituation are difficult to determine. The small confinement box, of course, clearly restricted the animal's movements so as to reduce the possibility of puff avoidance or attenuation by postural adjustments. And, the simultaneous presentation of the puff to both ends of the animal might have been particularly effective in maintaining startle amplitude. At any rate, the nonadapting air-puff-elicited startle response offers the potential advantage of a stable baseline against which to assess the effects of motivational variables.

Given the apparent difference in resistance to habituation between sound-induced and air-puff-elicited startle, it becomes important to know whether air-puff-elicited startle differs in other respects from the sound-induced type. Can, for example, the response to the puff of air be used to index the presence and strength of a conditioned emotional response such as fear? Experiment 2 was an attempt to answer this question by measuring air-puff-elicited startle magnitude in the presence of a CS previously paired with an aversive US.

The second study replicated, in most respects, the Brown, Kalish, and Farber (1951) experiment, which revealed that the amplitude of a startle response to a loud sound was enhanced in the presence of a presumed fear-eliciting CS. The basic procedural difference was in the use of the air puff.

\section{EXPERIMENT 2}

Method

Subjects Eighteen female albino rats, weighing $220-260 \mathrm{~g}$, served as Ss. All Ss had the same previous experiences as the animals in Experiment 1.

Appanatus. The apparatus is described in Experiment 1. A $5,000-\mathrm{Hz}$ tone produced by a Heathkit audio oscillator (Model AG-10) served as the CS. The CS was delivered through a 5-in. speaker located 8 in. diagonally below the confinement box containing $S$ and raised the sound level about $2 \mathrm{~dB}$ (ambient level, $60 \mathrm{~dB}$ ) on the $\mathrm{C}$ scale of a General Radio Co. sound-level meter (Model 1551-C). The US was a 0.5 -sec, 0.5-mA scrambled shock produced by a Grason-Stadler Model E1064GS shock generator.

Procedure. The Ss were assigned randomly, nine per group, to either a forward-conditioning (FC) or backward-conditioning (BC) group. Each $S$ received 25 conditioning trials on each of 4 successive days. Two test trials were presented at the end of each session. CS duration was $5.5 \mathrm{sec}$ for both groups. For the FC animals, CS onset occurred $5 \mathrm{sec}$ prior to US onset; the CS and US coterminated. CS onset occurred $15 \mathrm{sec}$ after US offset for the BC Ss. Both groups received conditioning trials at an average interval of $75 \mathrm{sec}$ (range, 60-90). On test trials, the startle stimulus was presented alone 5 sec after CS onset.

All Ss received three pretest trials, identical to the test trials, before the start of conditioning on Day 1 and following $5 \mathrm{~min}$ of habituation to the apparatus. On both pretest and test trials, E did not initiate the CS-startle stimulus sequence until $\mathrm{S}$ had assumed an immobile posture. This procedure was used because the results of Experiment 1 indicated that startle magnitude varied with S's activity at the moment of puff presentation. Test trials were initiated at approximately the same ITIs as conditioning trials.

\section{Results and Discussion}

Figure 2 shows the mean startle response curves for the FC and BC groups. An analysis of variance revealed that the effect of groups $(F=21.64, \mathrm{df}=1 / 16, p<.05)$, days $(F=3.78$, $d f=3 / 48, p<.05)$, and the Groups by Days interaction $(F=2.86$, $\mathrm{df}=3 / 48, p<.05$ ) were all significant. Subsequent $t$ tests indicated that the increase in mean startle response from pretest to Day 4 for Group FC was reliable $(t=4.26, d f=8, p<.05)$; the decrease in startle for Group BC was not $(t=2.31$, $\mathrm{df}=8, \mathrm{p}>.05$ )

The FC animals clearly showed fear conditioning. This outcome replicates the

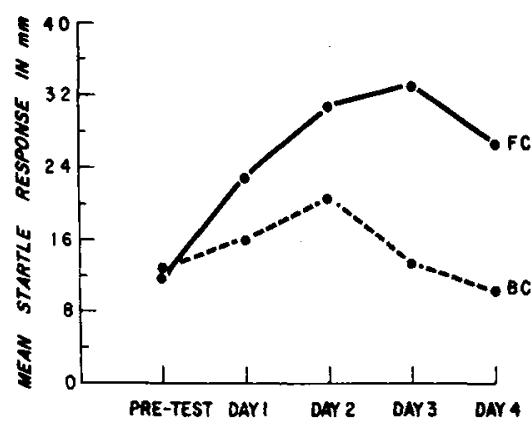

Fig. 2. Mean startle response in millimeters for the FC and BC groups on pretest trials and on test trials for Days 1-4.

findings of the original study by Brown, Kalish, and Farber (1951) using sound-induced startle. More generally, the results suggest that variations in the magnitude of air-puff-elicited startle can be employed to assess an animal's motivational level in the same manner that the sound-induced startle reflex has been employed.

\section{REFERENCES}

BROWN, J. S., KALISH, H. I., \& FARBER, I. E. Conditioned fear as revealed by magnitude of startle response to an auditory stimulus. Journal of Experimental Psychology, 1951, 41, 317-328.

HOFFMAN, H. S., \& SEARLE, J. L. Acoustic variables in the modification of startle reaction in the rat. Journal of Comparative \& Physiological Psychology, 1965, 60, 53-58.

MOYER, K. E. Startle response: Habituation over trials and days, and sex and strain differences. Joumal of Comparative \& Physiological Psychology, 1963, 56, 863-866.

WAGNER, A. R. Conditioned frustration as a learned drive. Journal of Experimental Psychology, 1963, 66, 142-148.

\section{NOTES}

1. This research was supported, in part, by National Institute of Mental Health Research Grant MH 11734-04 to J. S. Brown. Credit is due Professor Brown for the suggested use of the air puff as a startle stimulus.

2. This research was undertaken while the author was supported by Public Heaith Service Predoctoral Fellowship 1-F1-MH-41, 252-01 (PS). The author is now at State University College at Brockport, Brockport, New York 14420.

3. Brown, J. S. Unpublished startie response data collected at the University of lowa. 